\title{
Ceramic-on-ceramic versus ceramic- on-polyethylene in total hip arthroplasty: a comparative study at a minimum of 13 years follow-up
}

\author{
Malerba Giuseppe ${ }^{1}$, Basilico Mattia ${ }^{1,2}$, Bonfiglio Nadia ${ }^{1,2}$, Vitiello Raffaele ${ }^{1,2^{*}}$, Ruberto Pasquale ${ }^{1,2}$,
} $D^{\prime}$ Adamio Stefano ${ }^{1,2}$, Sirgiovanni Mattia ${ }^{3,4}$, De Santis Vincenzo ${ }^{1,2}$ and Maccauro Giulio ${ }^{1,2}$

\begin{abstract}
Background: Nowadays hip replacement is one of the most successful surgery in terms of clinical outcome and patient's satisfaction. Therefore, the choice of biomaterials in hip replacement is increasingly important with the aim of obtaining a long-term satisfaction of patient and a greater survivorship of the implants. Ceramic-on-polyethylene (COP) and ceramic-on-ceramic (COC) bearings are two common coupling used in total hip arthroplasty. The aim of this retrospective study was to compare clinical and radiological outcomes between patients treated using CoC and COPTHA at a mean follow-up of 15 years.
\end{abstract}

Methods: 86 patients, average age 65.6, were included in the study: 43 in group A bearing CoC and 43 in group B bearing CoP. Minimum follow-up was 13 years.

Primary outcome was a clinical evaluation assessed by HOOS and SF-12 questionnaires.

Secondary outcome was a radiological evaluation on a A-P pelvis $x$-ray calculating acetabular cup inclination and anteversion and detecting osteolysis.

Result: After a multivariate analysis was performed, our results show clinical outcomes in group B significantly better than in group A: statistically significant value $(p<0,05)$ was found in the mean HOOS-symptoms subscale $(83.0 \pm 15.4$ in Group A vs 90.3 \pm 12.2 in group B) in the SF-12 physical component score (39.7 \pm 11.0 in Group A vs $48.1 \pm 10.1$ in group B) and in HOOS (79.0 16 in Group A vs $87.0 \pm 16$ in group B). 3 squeaking was found in group A. The calculated mean acetabular cup inclination value was 44,87 in group $A$ and 44,5 in group $B$ and the mean socket version was 17,54 in group A and 15,10 in group B. No significant statistically relationship between radiographic parameters analyzed and clinical outcomes was noted.

Conclusion: The current results provide us important information about the THA long-term outcome. CoP offered significantly better results compared with CoC at long-term follow up, and thus it should be considered in the choose of bearing in THA.

Keywords: Hip, Replacement, Ceramic, Polyethylene, Wear, outcomes

*Correspondence: lele.vitiello@gmail.com

${ }^{1}$ Fondazione Policlinico Universitario Agostino Gemelli - IRCCS, Largo Agostino Gemelli 8, 00168 Rome, Italy

Full list of author information is available at the end of the article

\section{Background}

Total hip arthroplasty (THA) is an increasingly frequent treatment nowadays, and further increase in use of THA is expected, so as its optimal outcome [1]. original author(s) and the source, provide a link to the Creative Commons licence, and indicate if changes were made. The images or other third party material in this article are included in the article's Creative Commons licence, unless indicated otherwise in a credit line to the material. If material is not included in the article's Creative Commons licence and your intended use is not permitted by statutory regulation or exceeds the permitted use, you will need to obtain permission directly from the copyright holder. To view a copy of this licence, visit http://creativecommons.org/licenses/by/4.0/. The Creative Commons Public Domain Dedication waiver (http://creativeco mmons.org/publicdomain/zero/1.0/) applies to the data made available in this article, unless otherwise stated in a credit line to the data. 
Classically THA surgery was reserved for elderly patients. In recent years, however, there has been a reduction in the average age of patients undergoing THA and very young patients are subjected to it due to posttraumatic osteoarthritis, osteonecrosis, inflammatory arthritis, and congenital deformities (dysplasia of the hip, Legg-Calvè-Perthes disease, slipped capital femoral epiphysis) [2,3].

For this reason, the physical demands of the patients are increased, and more attention has been given to the biomaterials of the implants and their combinations, with the aim of obtaining a longer functionality of the implants.

Aseptic loosening following wear debris is classically considered the main cause of long-term failure after total hip arthroplasty [4].

Revision surgery is technically complex, it is linked to high risk of complications, morbidity and poor clinical outcome with the consequent economical burden on the healthcare system [5].

In this regard, the biomechanical studies are oriented in an attempt to minimize the wear between the various components, between the neo-femoral head and the acetabular liner.

Materials used for this purpose encompass metal, polyethylene, and bioceramics.

Combinations include metal-on-polyethylene, metalon-metal, ceramic-on-ceramic (CoC), ceramic-on-polyethylene $(\mathrm{CoP})$ and ceramic heads and metallic inserts.

Several studies have focused on the materials in hip arthroplasty: the ceramic-ceramic combination seems to better withstand mechanical wear and a longer implants life is expected $[6,7]$.

In this regard, it is important to compare the clinical outcomes and the satisfaction of patients undergoing total hip replacement (THR) using different materials and combinations.

The aim of this retrospective study is to compare the clinical and radiological outcome of patients treated using $\mathrm{CoC}$ and $\mathrm{CoP}$ at a minimum 13-years follow-up.

\section{Methods}

An integrated hospital system total joint replacement database was used to identify a cohort of patients with primary elective THAs performed in our hospital from January 1, 2005, to December 31, 2008. 103 subjects undergoing THA by the same surgeon in our hospital between 2005 and 2008 were recruited. Inclusion criteria were: patients undergoing primary THA from 2005 to 2008 performed by one senior surgeon; expression of informed consent to take part in the study; the same stem (Accolade-Stryker ${ }^{\circledR}$ Kalamazoo, Michigan, USA) and acetabular cup used for all subject (Trident-Stryker ${ }^{\circledR}$ Kalamazoo, Michigan, USA); patients aged $>18$ years.

Exclusion criteria were: patients undergoing revision hip arthroplasty due to mechanical complications, infectious complications or aseptic loosening.

As a primary outcome was chosen the comparison of clinical assessment between $\mathrm{CoC}$ vs $\mathrm{CoP}$ THAs.

Secondary outcome was radiographic evaluation on antero-posterior pelvis $\mathrm{x}$-ray.

In January 2021 subjects were contacted by telephone to confirm vital status and to schedule an outpatient visit.

The patients in group A received a ceramic head 2005 (BIOLOX $^{\circledR}$ Forte; CeramTec AG, Plochingen, Germany) coupled with a ceramic insert (BIOLOX-forte, CeramTec, Plochingen, Germany).

The patients in group B received a ceramic head 2005 (BIOLOX ${ }^{\circledR}$ Forte; CeramTec AG, Plochingen, Germany) coupled with a highly cross-linked polyethylene insert (Stryker Orthopaedics Mahwah, New Jersey, USA).

These bearing surfaces were chosen because already in the early 2000s they were considered the most interesting and potentially the best performing in terms of wear resistance and survival tought the exact 'best' option is nowdays unknown $[8,9]$.

All THAs were performed with the patient in the lateral position, using the Gibson-Moore posterolateral approach [10].

\section{Post-surgery routine}

No intra-articular drainage was positioned after surgery [11]; postoperatively, the patient's pain was treated with paracetamol, NSAIDs or Oxycodone as needed.

Patients were weightbearing as tolerated on the leg involved.

One day postoperative occupational and physical therapy were initiated, and walking was allowed with crutches. No antibiotic was used in post-surgery protocol.

Antithrombotic prophylaxis consisted in the use of graduated compression stockings and low-molecularweight Heparin once daily for 5 weeks post-surgery.

\section{Clinical evaluation}

After their expression of consent, during an external consultation the patients were clinically evaluated for restoring range of motion, presence of hip pain and evocable audible noise of the hip as squeaking, clicking, grinding.

Squeaking has been considered as a high-pitched audible sound from the hip; clicking as a "click" that occurs during hip movement or walking; grinding as "crepitus" during movement [12]. 
At the moment of the visit the subjects completed two questionnaires: HOOS (Hip disability and Osteoarthritis Outcome Score) e SF12 (12-Item Short Form Survey).

The HOOS is a 40 -item self-reported questionnaire comprising 5 subsets: pain, symptoms, activities of daily living, sport and hip related quality of life. The score is expressed as a percentage with a higher value corresponding to a higher patient satisfaction $[13,14]$.

The SF12 is a self-reported outcome measure assessing the impact of health on an individual's everyday life, being a shortened version of the SF-36 and it is often used as a quality-of-life measure $[15,16]$.

Total scores allow to construct two synthetic indices: a physical health index (SF-12 P) and a mental health index (SF-12M). The lower the score of the two indices, the greater the level of disability.

\section{Radiological evaluation}

During the outpatient consultation, an antero-posterior pelvis $\mathrm{x}$-ray was obtained, and a radiographic evaluation was performed to calculate hip socket inclination and anteversion.

The inclination was measured on standard X-ray as the angle between a line drawn along the opening of the acetabular component and one joining the ischial tuberosities [17] (Fig.1).

Planar anteversion is the rotation of the acetabular face along the axis defined by the intersection of the coronal plane and the plane of the acetabular face. It is calculated on plane $\mathrm{x}$-ray following the method explained by $\mathrm{V}$. Bachhal et al. which proved to be simple to perform and reliable [18] (Fig. 2).
Finally, areas of osteolysis were reported on plane radiographs according to (A) Gruen zones and (B) De Lee and Charnley zones. (Fig. 3). Osteolysis was defined as the appearance of a radiolucid zone in the pelvic area around the acetabulum and in the femoral shaft near the femoral stem [19] (Fig. 3).

\section{Statistical analyses}

STATA 16 was used for statistical analyses. We considered $P$ values $<0.05$ to be significant.

Since the variables we investigated were continuous scales we first examined them by mean of T-Test and then we added adjusting factors performing a multiple linear regression analysis. Adjusting factors were chosen in order to keep low the risk of overfitting the model, while maintaining in it factors known to affect the outcome.

\section{Results}

A total of 103 Total Hip Arthroplasties were enlisted in our study.

$17(16,5 \%)$ were excluded: 10 patients (11\%) due to loss of follow-up and 7 patients $(6,5 \%)$ were revised due to THA dislocation (2 hips), aseptic loosening (3 hips) and periprosthetic fracture (2 hips)

Finally, 86 patients were enrolled in the study, divided into two groups: group A CoC (43 subjects) consisting of patients with the ceramic-ceramic bearings and group B CoP (43 subjects) with ceramic-polyethylene bearings (Fig. 4).

In group A there were 20 female and 23 males, in group $B$ there were 22 female and 21 males.



Fig. 1 Acetabular cup inclination. Method of calculation of acetabular cup inclination on AP pelvic radiographs as the angle formed between a line drawn along the opening of the acetabular component and one joining the ischial tuberosities 


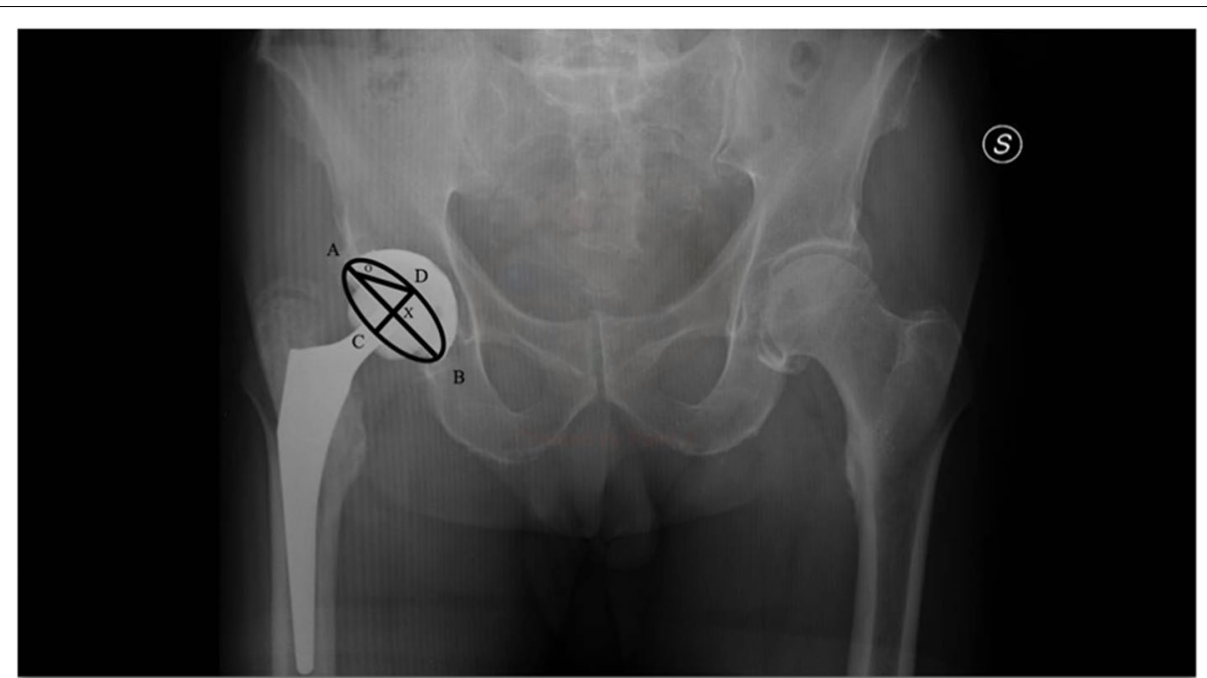

Fig. 2 Acetabular cup ante-version. Calculation of acetabular cup anteversion on AP pelvis radiograph using method explained by V. Bachhal et al. $A B=$ major axis of the ellipse, $C D=$ minor axis of the ellipse represented acetabular component $X O D=$ the calculated angle of anteversion

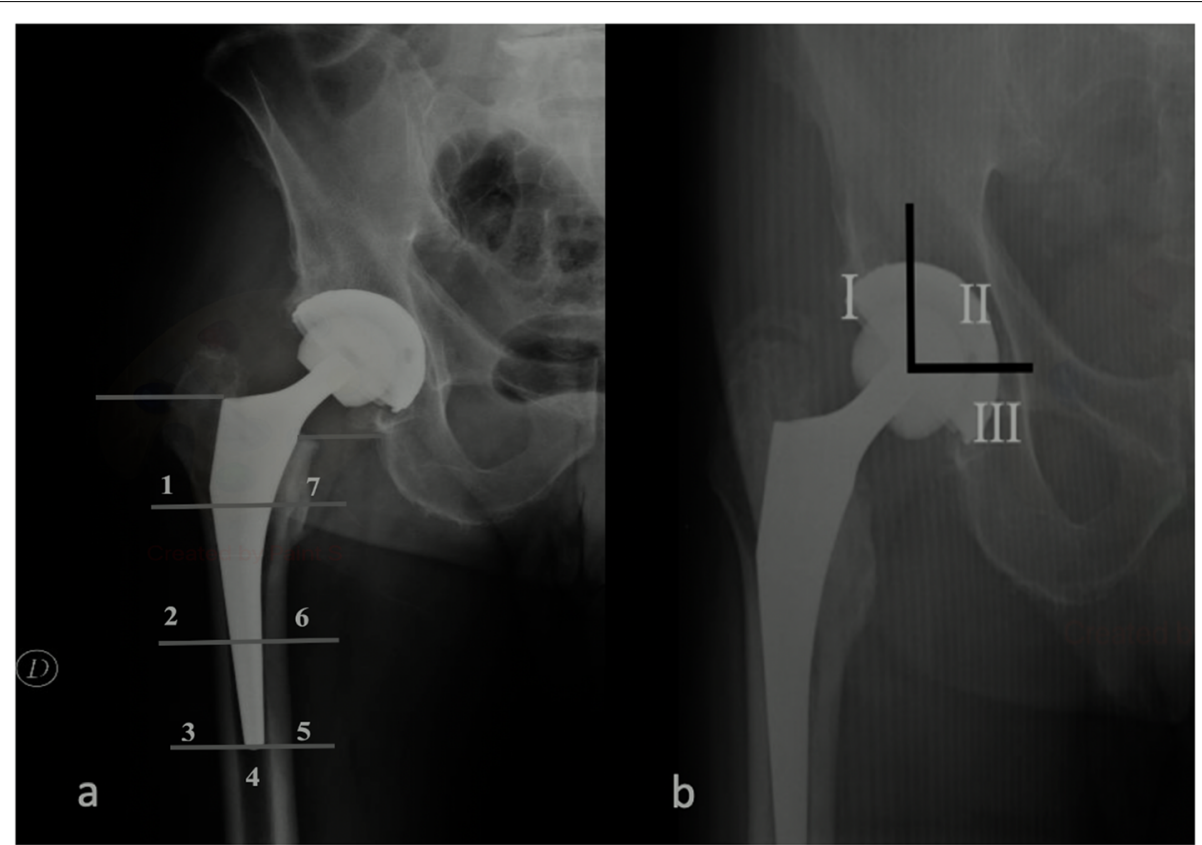

Fig. 3 Areas of osteolysis. 7 areas of femoral osteolysis according to Gruen zones (a) and 3 areas of peri-acetabular osteolysis according to De Lee and Charnley zones (b)

Average age of the patients was 65.6 years, with a mean of 63.4 years for group A (SD 6.5) and 67.8 years for group B (SD 11).

The average BMI was 25.9 (SD 3.3) for the group B and 27 (SD3.1) for the group A.

The mean follow-up was 15 years (SD 1) with a minimum of 13 years.
All parameters showed an asymmetry between -2 and +2 , suggestive of a normal distribution.

The adjusted results, for age, BMI and gender, showed no significant difference between the two groups regarding HOOS-P, HOOS-A, HOOS-Sp, HOOS-Q, SF12p and SF12M once the analyses were corrected for the presence of the aforementioned factors (Table 1). 


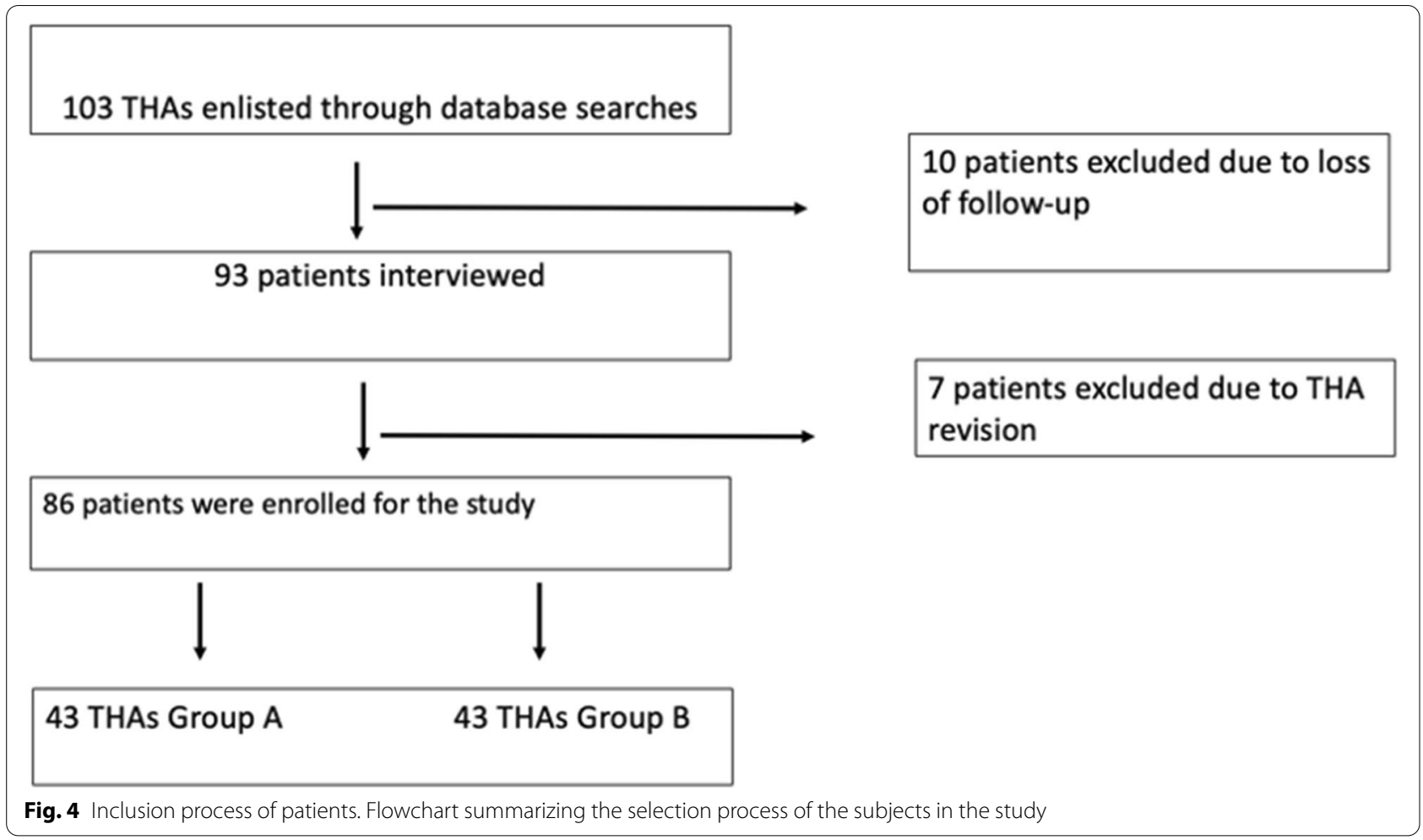

Table 1 Clinical outcomes

\begin{tabular}{|c|c|c|c|c|}
\hline & Group A (CoC) & Group B (CoP) & p & $95 \% \mathrm{Cl}$ \\
\hline Dos $-S$ & & 9 & $0.04^{*}$ & 59 \\
\hline HOOS - P & 85.5 (SD 11.8) & (1.4 (JU) & 0.052 & -0.04 to 13.06 \\
\hline HOOS - SP & 79.4 (SD 23.7) & 79.4 (SD 23.7) & 0.08 & -1.51 to 24.03 \\
\hline $\mathrm{HOOS}-\mathrm{A}$ & 77.9 (SD 17.7) & 86.8 (SD 17.7) & 0.06 & -0.46 to 20.52 \\
\hline HOOS - TOTAL & 79 (SD 16) & 87 (SD 16) & $0.04^{*}$ & 0.24 to 17.90 \\
\hline SF-12P & 39.7 (SD 11.0) & 48.1 (SD 10.1) & $0.02^{*}$ & 3.60 to 15.03 \\
\hline SF-12M & 46.1 (SD 11.3) & 49.8 (SD 8.6) & 0.14 & -1.13 to 9.97 \\
\hline
\end{tabular}

Data were reported as absolute value and in brackets SD. The * underline statistical significance

The HOOS-S Score however diverged significantly from this trend, being significantly higher in the group $B$ than in the Group A (CI: 0.33 to $15.59, p=0.04$ ).

A subsequent analysis also combined the scores to obtain a so called "HOOS total". According to these analyses the group B showed a score of 9.07 points higher than the Group A (CI: 0.24 to $17.90, \mathrm{p}=0.04)$. 4 patients in the group A (3/43 patients, $6 \%$ ) reported occasionally hearing sounds from their THA: the reported sound is like a "squeak", no such anomaly was reported in group B.

In group $A$ the calculated mean socket inclination value was 44.87 and mean socket version was 17.54 . In group B the mean inclination was 44.5 and the mean version was
16.10. Pearson Correlation Coefficient was used to analyze relationship between anteversion cup and clinical outcomes, no statistical difference was noted.

Finally, we identified one osteolysis in zone 1 according with Gruen zone in group A (1/43 patients, $2 \%)$ and two osteolysis ( 1 in zone 1 according with De Lee and Charnley classification and 1 in zone 7 according with Gruen zones) in group B (2/43 patients, $4 \%)$, no statistical difference was noted $(p=0.5)$.

\section{Discussion}

Long-term patient satisfaction and implant survival depends on their wear resistance and it is associated with the particulate debris' release because of wearing [20].

In hip prosthetics, the study of tribology has always been a debated topic. Our study is our contribution on the debate about materials: comparing functional outcome and satisfaction between CoC and CoP after THR at minimum 13 years $\mathrm{f}-\mathrm{u}$, our results show a statistically significant difference between the two groups about clinical outcome in favor of $\mathrm{CoP}$ group versus $\mathrm{CoC}$ group.

Ceramic on ceramic bearing were presented as a solution to wear, given the good wear resistance of ceramic components [21-23].

Several authors proved this coupling allows to achieve good medium-long term outcome, especially in young patients: Solarino et al. reported excellent results in 200 
Ceramic-on-Ceramic cementless hip arthroplasties in young patients rated 5-24years follow-up after surgery [24-28].

Likewise, analyzing 113 primary THAs in 91 patients younger than 20 years at the time of surgery, Hannouche et al. reported a satisfactory outcome at 8.8 years-medium follow up: the mean HOOS score was 79.3 \pm 13.8 [29].

Our study also showed a good long-term outcome with a HOOS mean value of 79 (SD 16) in our sample patient treated using $\mathrm{CoC}$ bearing, despite a higher average age.

However, $\mathrm{CoC}$ bearing is related to important drawbacks: potential for breakage and noisy after hip movement.

Actually, the breakage of components is not a common occurrence: according to a recent meta-analysis the rate of ceramic fracture was 0.9/1000 patient-year in THA using Forte ceramic and 0.5/1000 patient-year using Delta ceramic [30].

Liner fracture is reported in literature with a higher frequency than head, being between 0.13 to $1.1 \%$ [31, 32].

Furthermore, the introduction of the latest generations of ceramic seems to have solved the problem of head fracture and greatly reduced problem of the liner breakage. Indeed, our study, analyzing ceramics from 2005 to 2008, did reveal no breakage of component in the $\mathrm{CoC}$ sample under examination.

Another problem related to $\mathrm{CoC}$ bearing consists of unwanted sounds from the hip after THA. The main reported noise is the squeaking. Although it does not affect the functional outcome of the THA, it plays an important role in patient satisfaction [33].

In some cases the squeaking was so unbearable that hip-replacemente was required, despite the full functionality to the hip [34].. There is no agreement about the real rates of ceramic-on-ceramic squeaking, although it seems to fluctuate between 1 and $20.9 \%[35,36]$.

We found three (6\% of $\mathrm{CoC}$ group) squeakings in $\mathrm{CoC}$ group, but no patient with "noisy hip" required a re-operation because of that.

Yet, with ceramic- on polyethylene bearing being a good alternative to $\mathrm{CoC}$, the choice of the best materal coupling is still a matter of debate.

However, the use of polyethylene, especially old generation polyethylene, is burdened by a greater accumulation of wear debris and consequent osteolysis [37].

We investigated the presence of osteolysis on planar $\mathrm{x}$-rays and identified one osteolysis in group $\mathrm{A}$ and two in group B. After an analysis they did not seem to influence the patient functional outcome in our groups.

After a multivariate analysis was performed, our results showed the degree of satisfaction of patients in group B being significantly better than in group $\mathrm{A}$, measured by the HOOS and SF-12 questionnaire.
This result differs from many studies comparing the outcomes of $\mathrm{CoC}$ and $\mathrm{CoP}$ in THA that showed no significant differences between the two groups in terms of pain, stiffness, patient satisfaction, component wear, and failure or revision rate [38-43].

These data explain why the choice of materials in THA is still matter of debate nowadays and the consensus on material components has not yet been reached.

Furthermore, the use of the polyethylene liner has an important economic value, resulting in savings compared to the higher cost of the ceramic [44].

\section{Radiographic evaluation}

The correct orientation of the acetabular cup is essential for a good outcome after a total hip arthroplasty.

Lewinnek has identified a safe zone of anteversion of $15^{\circ}+/-10^{\circ}$ and inclination of $40^{\circ}+/-10^{\circ}$ in which the dislocation rate is lower than outside this range $[45,46]$.

Grammatopoulos et al., demonstrated the best outcomes were achieved with an inclination of $45^{\circ} \pm 5^{\circ}$ and an anteversion of $25^{\circ} \pm 5^{\circ}(\Delta$ Oxford Hip Score.

$>26$ ), after analyzing the orientation of acetabular component in 1070 primary THR with hard-on-soft [47].

Many authors tried to identify the correct orientation of the cup, but even more have tried to devise methods to obtain the correct and desired orientation of the cup intraoperatively [48-50].

The orientation of the sockets analyzed in our study fall within the Lewinnek safe zone, and no significant correlation was found between socket orientation and clinical outcome.

\section{Limits}

The results of this study must be considered in light of its retrospective nature and its small sample size, being its major limitations. Because of that, no preoperative evaluation could be obtained to correlate the pre- and postoperative outcomes, thus including underlying diseases influencing the parameters considered.

For the same reason, the long-term functionality of the implant was not examined, but the main focus was put on the evaluation of the degree of patient satisfaction in relation to material components years after surgery.

Despite these weaknesses, some strengths of the study need to be underscored, among which are surely the long follow-up and the uniformity of the sample. To the current authors' knowledge, in the literature few studies compare bearings in hip replacements at such a long follow-up.

Moreover, we tried to limit the bias by including THAs performed by the same surgeon using the same stem and the same acetabular cup. 
This paper receives funding of Orthopedic and Traumatology School of Università Cattolica del Sacro Cuore - Roma. The funders did not play any role in the design of the study, the collection, analysis, and interpretation of data, or in writing of the manuscript.

\section{Conclusion}

Biomaterial remains a debated topic for Hip Arthroplasty. Despite that, the current results provide us important information about the long-term good outcome of CoP bearing compared to CoC's ones. In fact, it is suggested that the low wear clinical performance related to ceramic-on-ceramic bearings can be challenged by the performance of highly cross-linked polyethylene, also thanks to the reliability of the new polyethylene which seems to have overcome the wear problems related to the first generation of polyethylene. In view of the results, the bearing surface Ce-Po seems to be more resistant to wear than previously thought and could be considered as an option even in young patients with high functional demand.

However, further prospective studies would be needed, with a larger sample, to obtain more complete information about the bearing surface and the THAs survivorship.

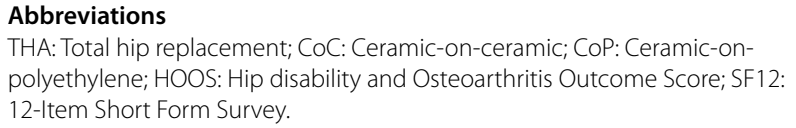

THA: Total hip replacement; CoC: Ceramic-on-ceramic; CoP: Ceramic-onpolyethylene; HOOS: Hip disability and Osteoarthritis Outcome Score; SF12: 12-Item Short Form Survey.

\section{Acknowledgements}

None.

\section{About this supplement}

This article has been published as part of BMC Musculoskeletal Disorders Volume 22 Supplement 2 2021: All about the hip. The full contents of the supplement are available at https://bmcmusculoskeletdisord.biomedcentral.com/ articles/supplements/volume-22-supplement-2.

\section{Authors' contributions}

G.M. and V.D.S. - design study. P.R. and N.B. - data collecting. R.V. and M.B. - preparing manuscript. M.S. - data analysis. G.M. and S.D.D. - revising manuscript content. All authors have read and approved the final manuscript.

\section{Funding}

Publication costs are funded by Orthopedic and Traumatology School of Università Cattolica del Sacro Cuore - Roma.

'The funders did not play any role in the design of the study, the collection, analysis, and interpretation of data, or in writing of the manuscript.

\section{Availability of data and materials}

The datasets used and/or analyzed during the current study are available from the corresponding author on reasonable request.

\section{Declarations}

\section{Ethics approval and consent to participate}

All procedures performed in the current study were in accordance with the 1964 Helsinki declaration and its later amendments. Written informed consent was obtained from all individual participants included in the study. The study design was approved by the Orthopedic and Traumatology Institute and School Council.

\section{Consent for publication}

All patients signed an appropriate release to use their health and sensitive data and to be enrolled in the study.

\section{Competing interests}

The authors declare no potential conflict of interest.

\section{Author details}

${ }^{1}$ Fondazione Policlinico Universitario Agostino Gemelli - IRCCS, Largo Agostino Gemelli 8, 00168 Rome, Italy. ${ }^{2}$ Università Cattolica Del Sacro Cuore, Roma, Italy. ${ }^{3}$ Department of Medical Oncology and Pneumology, University Hospital Tuebingen, Tuebingen, Germany. ${ }^{4}$ Cluster of Excellence iFIT (EXC 2180) "Image-Guided and Functionally Instructed Tumor Therapies", University of Tuebingen, Tuebingen, Germany.

Received: 8 December 2021 Accepted: 9 December 2021

Published online: 17 January 2022

\section{References}

1. Singh JA, Yu S, Chen L, Cleveland JD. Rates of Total joint replacement in the United States: future projections to 2020-2040 using the National Inpatient Sample. J Rheumatol. 2019;46:1134-40.

2. AOANJRR. Australian Orthopaedic Association National Joint Replacement Registry (AOANJRR). Hip, knee \& shoulder arthroplasty: 2018 annual report. Australian Orthopaedic Association National Joint Replacement Registry (AOANJRR). Hip, knee \& shoulder arthroplasty: 2018 annual report. https://aoanjrr.sahmri.com/documents/10180/576950/Hip\%2C\% 20Knee\%20\%26\%20Shoulder\%20Arthroplasty; 2018; 2018.

3. Meschini C, Cauteruccio M, Oliva MS, Sircana G, Vitiello R, Rovere G, et al. Hip and knee replacement in patients with ochronosis: clinical experience and literature review. Orthop Rev (Pavia). 2020;12(Suppl 1):8687.

4. Swedish Hip Arthroplasty RegisterAnnual Report 2009. https://registerce ntrum.blob.core.windows.net/shpr/r/Annual-report-2009-HyWIK8Tol.pdf. Accessed 30 Dec 2021.

5. Bozic KJ, Kamath AF, Ong K, Lau E, Kurtz S, Chan V, et al. Comparative epidemiology of revision arthroplasty: failed THA poses greater clinical and economic burdens than failed TKA. Clin Orthop Relat Res. 2015:473:2131-8

6. Merola M, Affatato S. Materials for Hip Prostheses: A Review of Wear and Loading Considerations. Materials (Basel). 2019;12:495.

7. Lee J-M. The current concepts of Total hip arthroplasty. Hip Pelvis. 2016;28:191-200.

8. Jenabzadeh AR, Haddad FS. Novel strategies in joint replacement. Br J Hosp Med (Lond). 2006:67:294-8.

9. Navarro M, Michiardi A, Castaño O, Planell JA. Biomaterials in orthopaedics. J R Soc Interface. 2008;5:1137-58.

10. Kelmanovich D, Parks ML, Sinha R, Macaulay W. Surgical approaches to total hip arthroplasty. J South Orthop Assoc. 2003;12:90-4.

11. Basilico M, Vitiello R, Liuzza F, Minutillo F, Ruberto P, Matrangolo MR, et al. Efficacy of postoperative drainage in total knee arthroplasty: review of the literature. Orthop Rev (Pavia). 2020;12(Suppl 1):8663.

12. William L. Walter Reza Jenabzdadeh Carina Reinhardt Practical Guide for Handling Noises in Hard-on-Hard Bearings (Springer) - https://orthoinfo aaos.org/en/diseases\%2D\%2Dconditions/osteoarthritis-of-the-hip.

13. Nilsdotter AK, Lohmander LS, Klässbo M, Roos EM. Hip disability and osteoarthritis outcome score (HOOS) - validity and responsiveness in total hip replacement. BMC Musculoskelet Disord. 2003:4:10.

14. Torre M, Luzi I, Mirabella F, Del Manso M, Zanoli G, Tucci G, et al. Cross-cultural adaptation and validation of the Italian version of the Hip disability and Osteoarthritis Outcome Score (HOOS). Health Qual Life Outcomes. 2018:16:115.

15. Ware JE. SF-36 health survey update. Spine (Phila Pa 1976). 2000:25:3130-9. 
16. Ware J, Kosinski M, Keller SD. A 12-item short-form health survey: construction of scales and preliminary tests of reliability and validity. Med Care. 1996:34:220-33.

17. Woo RY, Morrey BF. Dislocations after total hip arthroplasty. J Bone Joint Surg Am. 1982;64:1295-306.

18. Bachhal V, Jindal N, Saini G, Sament R, Kumar V, Chouhan D, et al. A new method of measuring acetabular cup anteversion on simulated radiographs. Int Orthop. 2012;36:1813-8.

19. Perez Alamino R, Casellini C, Baňos A, Schneeberger EE, Gagliardi SA, Maldonado Cocco JA, et al. Prevalence of periprosthetic osteolysis after total hip replacement in patients with rheumatic diseases. Open Access Rheumatol. 2012;4:57-62.

20. Hallab NJ, Jacobs JJ. Biologic effects of implant debris. Bull NYU Hosp Jt Dis. 2009;67:182-8.

21. Kang B-J, Ha Y-C, Ham D-W, Hwang S-C, Lee Y-K, Koo K-H. Third-generation alumina-on-alumina total hip arthroplasty: 14 to 16-year follow-up study. J Arthroplast. 2015;30:411-5.

22. Maccauro G, Bianchino G, Sangiorgi S, Magnani G, Marotta D, Manicone PF, et al. Development of a new zirconia-toughened alumina: promising mechanical properties and absence of in vitro carcinogenicity. Int J Immunopathol Pharmacol. 2009;22:773-9.

23. Piconi C, Maccauro G, Muratori F, Brach Del Prever E. Alumina and zirconia ceramics in joint replacements. J Appl Biomater Biomech. 2003;1:19-32.

24. Solarino G, Zagra L, Piazzolla A, Morizio A, Vicenti G, Moretti B. Results of 200 consecutive ceramic-on-ceramic Cementless hip arthroplasties in patients up to 50 years of age: a 5-24 years of follow-up study. J Arthroplast. 2019;34:S232-7.

25. Wang T, Sun J-Y, Zhao X-J, Liu Y, Yin H-B. Ceramic-on-ceramic bearings total hip arthroplasty in young patients. Arthroplast Today. 2016;2:205-9.

26. Saracco M, Passiatore M, Cazzato G, Ziranu A, Piconi C, Maccauro G. Use of ceramic bearings in hip arthroplasty: correct implantation and review of clinical and radiographic results. J Biol Regul Homeost Agents. 2020;34(4 Suppl. 3):237-42 Congress of the Italian Orthopaedic Research Society.

27. Piconi C, De Santis V, Maccauro G. Clinical outcomes of ceramicized ball heads in total hip replacement bearings: a literature review. J Appl Biomater Funct Mater. 2017;15:e1-9.

28. D’Adamio S, Maccauro G, Malerba G, Piconi C. Ceramic Roles in Aseptic Loosening: In Vivo Macro- and Microscopic Histological Evaluation. Key Eng Mater. 2017;758:228-33.

29. Hannouche D, Devriese F, Delambre J, Zadegan F, Tourabaly I, Sedel L et al. Ceramic-on-ceramic THA implants in patients younger than 20 years. Clin Orthop Relat Res. 2016;474:520-7.

30. Yoon B-H, Park J-W, Cha Y-H, Won S-H, Lee Y-K, Ha Y-C, et al. Incidence of ceramic fracture in contemporary ceramic-on-ceramic Total hip arthroplasty: a Meta-analysis of proportions. J Arthroplast. 2020;35:1437-1443. e3.

31. Colwell CW, Hozack WJ, Mesko JW, D'Antonio JA, Bierbaum BE, Capello WN, et al. Ceramic-on-ceramic total hip arthroplasty early dislocation rate. Clin Orthop Relat Res. 2007;465:155-8.

32. Howard DP, Wall PDH, Fernandez MA, Parsons H, Howard PW. Ceramicon-ceramic bearing fractures in total hip arthroplasty: an analysis of data from the National Joint Registry. Bone Joint J. 2017;99-B:1012-9.

33. Barrow JA, Divecha HM, Panchani S, Boden R, Chitre A, Gambhir A, et al. Is patient satisfaction related to patient reported sounds from ceramic on ceramic total hip arthroplasty? A study of 265 hips. Eur J Orthop Surg Traumatol. 2019;29:1243-51.

34. Matar WY, Restrepo C, Parvizi J, Kurtz SM, Hozack WJ. Revision hip arthroplasty for ceramic-on-ceramic squeaking hips does not compromise the results. J Arthroplast. 2010;25(6 Suppl):81-6.

35. Keurentjes JC, Kuipers RM, Wever DJ, Schreurs BW. High incidence of squeaking in THAs with alumina ceramic-on-ceramic bearings. Clin Orthop Relat Res. 2008;466:1438-43.

36. Huo MH, Parvizi J, Gilbert NF. What's new in hip arthroplasty. J Bone Joint Surg Am. 2006;88:2100-13.

37. Hernigou P, Zilber S, Filippini P, Poignard A. Ceramic-ceramic bearing decreases osteolysis: a 20-year study versus ceramic-polyethylene on the contralateral hip. Clin Orthop Relat Res. 2009;467:2274-80.

38. Amanatullah DF, Landa J, Strauss EJ, Garino JP, Kim SH, Di Cesare PE. Comparison of surgical outcomes and implant wear between ceramicceramic and ceramic-polyethylene articulations in total hip arthroplasty. J Arthroplast. 2011;26(6 Suppl):72-7
39. Beaupre LA, Manolescu A, Johnston DWC. A randomized trial of ceramicon-ceramic bearing versus ceramic-on-crossfire-polyethylene bearing in total hip arthroplasty: five-year outcomes. J Arthroplast. 2013;28:485-9.

40. Epinette J-A, Manley MT. No differences found in bearing related hip survivorship at 10-12 years follow-up between patients with ceramic on highly cross-linked polyethylene bearings compared to patients with ceramic on ceramic bearings. J Arthroplast. 2014;29:1369-72.

41. Dong Y-L, Li T, Xiao K, Bian Y-Y, Weng X-S. Ceramic on ceramic or ceramic-on-polyethylene for Total hip arthroplasty: a systemic review and Meta-analysis of prospective randomized studies. Chin Med J. 2015;128:1223-31.

42. Atrey A, Wolfstadt Jl, Hussain N, Khoshbin A, Ward S, Shahid M, et al. The ideal Total hip replacement bearing surface in the young patient: a prospective randomized trial comparing alumina ceramic-on-ceramic with ceramic-on-conventional polyethylene: 15-year follow-up. J Arthroplast. 2018;33:1752-6.

43. Beaupre LA, Al-Houkail A, Johnston DWC. A randomized trial comparing ceramic-on-ceramic bearing vs ceramic-on-crossfire-polyethylene bearing surfaces in Total hip arthroplasty. J Arthroplast. 2016;31:1240-5.

44. Carnes KJ, Odum SM, Troyer JL, Fehring TK. Cost analysis of ceramic heads in primary Total hip arthroplasty. J Bone Joint Surg Am. 2016;98:1794-800.

45. McKibbin B. Anatomical factors in the stability of the hip joint in the newborn. J Bone Joint Surg (Br). 1970;52:148-59.

46. Lewinnek GE, Lewis JL, Tarr R, Compere CL, Zimmerman JR. Dislocations after total hip-replacement arthroplasties. J Bone Joint Surg Am. 1978;60:217-20.

47. Grammatopoulos G, Thomas GER, Pandit H, Beard DJ, Gill HS, Murray DW. The effect of orientation of the acetabular component on outcome following total hip arthroplasty with small diameter hard-on-soft bearings. Bone Joint J. 2015;97-B:164-72.

48. Khalifa AA, Bakr HM, Said E, Mahran MA. Technical note on using intraoperative smartphone applications to adjust cup inclination angle during Total hip arthroplasty (THA). Arch Bone Jt Surg. 2020;8:734-8.

49. Peng H-M, Feng B, Chen $X$, Wang $Y-O$, Bian $Y-Y$, Wang W, et al. Usefulness of a simple preoperative planning technique using plain $X$-rays for direct anterior approach for Total hip arthroplasty. Orthop Surg. 2021;13:145-52.

50. Kadar T, Furnes O, Aamodt A, Indrekvam K, Havelin LI, Haugan K, et al. The influence of acetabular inclination angle on the penetration of polyethylene and migration of the acetabular component: a prospective, radiostereometric study on cemented acetabular components. J Bone Joint Surg (Br). 2012;94:302-7.

\section{Publisher's Note}

Springer Nature remains neutral with regard to jurisdictional claims in published maps and institutional affiliations.

Ready to submit your research? Choose BMC and benefit from

- fast, convenient online submission

- thorough peer review by experienced researchers in your field

- rapid publication on acceptance

- support for research data, including large and complex data types

- gold Open Access which fosters wider collaboration and increased citations

- maximum visibility for your research: over $100 \mathrm{M}$ website views per year

At BMC, research is always in progress.

Learn more biomedcentral.com/submissions 